Revista Iberoamericana de Micología

www.elsevier.es/reviberoammicol

Original article

\title{
Prevalence of Malassezia species in patients with pityriasis versicolor in Rosario, Argentina
}

\author{
Silvana Ramadán*, Maximiliano Sortino, Lucía Bulacio, María Laura Marozzi, Clara López, Laura Ramos

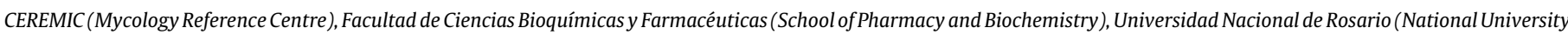 \\ of Rosario), Suipacha 531, Rosario (2000), Argentina
}

\section{A R T I C L E I N F O}

\section{Article history:}

Received 28 September 2010

Accepted 2 March 2011

Available online 17 March 2011

\section{Keywords:}

Malassezia

Identification

Epidemiology

\begin{abstract}
A B S T R A C T
Background: Malassezia species are considered opportunistic yeasts of increasing clinical importance. These lipophilic yeasts are associated with various human diseases, especially pityriasis versicolor (PV), a chronic superficial scaling dermatomycosis.

Aims: The aim of this study was to isolate, identify and analyze the distribution of the different species of Malassezia in patients with PV in Rosario city (Argentina).

Methods: A total of 264 clinical samples were studied. Isolates were identified on the basis of microscopic observation of cells, and physiological properties, such as the presence of catalase, ability to use Tween compounds, splitting of esculin, and morphology, color and precipitate production on chromogenic agar CHROMagar-Malassezia medium (CHROMM).

Results: The highest prevalence of PV in this study was observed in the 25- to 45-year-old group. No differences were found in the development of PV between sexes. The most affected areas of body were the trunk and face. Malassezia sympodialis (51\%) was the most commonly isolated species, followed in frequency by M. globosa (40\%), Malassezia furfur (7\%), Malassezia obtusa (1\%) and Malassezia slooffiae (1\%). Conclusions: The success for a correct identification of these yeasts is important to improve our knowledge about their epidemiological role in PV and also to detect the appearance of strains which are resistant to the commonly used antifungal drugs.
\end{abstract}

(c) 2010 Revista Iberoamericana de Micología. Published by Elsevier España, S.L. All rights reserved.

\section{Prevalencia de especies de Malassezia en pacientes con Pitiriasis versicolor en Rosario, Argentina}

\section{R E S U M E N}

Antecedentes: Las especies de Malassezia son consideradas levaduras oportunistas de importancia clínica creciente. Estas levaduras lipófilas están asociadas con diversas enfermedades humanas, especialmente la pitiriasis versicolor (PV), una dermatomicosis superficial crónica.

Objetivos: El objetivo de este estudio fue aislar, identificar y analizar la distribución de diferentes especies de Malassezia en pacientes con PV en la ciudad de Rosario, Argentina.

Métodos: Se estudiaron 264 muestras clínicas y los aislamientos fueron identificados según la observación microscópica de las células, propiedades fisiológicas tales como, presencia de catalasa, habilidad para utilizar compuestos Tween, desdoblamiento de la esculina y la descripción del color, morfología y formación de precipitado empleando el medio cromógeno CHROMagar Malassezia (CHROMM). Resultados: La mayor prevalencia de PV, en este estudio, fue encontrada en el grupo de 25-45 años de edad, no encontrandose diferencias con respecto al sexo. Las áreas más afectadas fueron tronco y cara. Malassezia sympodialis (51\%) fue la especie más aislada, seguida por Malassezia globosa (40\%), Malassezia furfur (7\%), Malassezia obtusa (1\%) y Malassezia slooffiae (1\%).

Conclusiones: La importancia de una correcta identificación de estas levaduras es necesaria para el conocimiento de su rol epidemiológico en la PV y también para detectar la presencia de cepas resistentes a los antifúngicos.

(C) 2010 Revista Iberoamericana de Micología. Publicado por Elsevier España, S.L. Todos los derechos reservados.

\footnotetext{
* Corresponding author.

E-mail address: sramadan@fbioyf.unr.edu.ar (S. Ramadán).
}

1130-1406/\$ - see front matter @ 2010 Revista Iberoamericana de Micología. Published by Elsevier España, S.L. All rights reserved. doi:10.1016/j.riam.2011.03.001 
The genus Malassezia comprises lipophilic yeasts belonging to the normal cutaneous microbiota of humans and warm-blooded animals, ${ }^{16}$ and can be cultured from almost all body areas. However, they may become pathogenic under certain conditions and are associated with a broad spectrum of clinical infections as pityriasis versicolor (PV), folliculitis, seborrheic dermatitis, some forms of atopic dermatitis, confluent and reticulate papillomatosis, and even systemic infections. $4,7,23,28,30,35$

PV is common in late teens and young adults of both sexes, and is characterized by well-demarcated scaling patches with variable pigmentation. ${ }^{12}$ Although PV was described at the beginning of the nineteenth century; its etiological agents have been a matter of debate. This controversy may be due to various morphological features and fastidious growth requirements of Malassezia yeasts in vivo.

Morphology, ultrastructure, physiology (catalase reaction, splitting of esculin, lipids assimilation pattern, utilization of Cremophor $\mathrm{EL}$, and thermotolerance), and molecular biology of Malassezia have been recently revised. ${ }^{13}$ This genus includes the following fourteen species: Malassezia pachydermatis, Malassezia furfur, Malassezia sympodialis, Malassezia globosa, Malassezia obtusa, Malassezia restricta, Malassezia slooffiae, Malassezia caprae,3,14,15,17,18,29,39 Malassezia dermatis, ${ }^{41}$ Malassezia japonica, ${ }^{42}$ Malassezia equina, ${ }^{3}$ Malassezia nana, ${ }^{24}$ Malassezia yamatoensis ${ }^{43}$ and Malassezia cuniculi sp. nov. ${ }^{4}$ M. nana, M. equina, $M$. caprae and Malassezia cuniculi sp. nov., have only been isolated from domestic animals. ${ }^{4}$ There is little information about the epidemiology and ecology of Malassezia species; hence, the clinical significance of these species is not fully distinguished. Some species are polymorphic, in particular M. furfur; others have fastidious requirements for growth, and their maintenance in subculture is difficult, such as M. globosa and $M$. restricta. Variations in susceptibility to antifungal drugs have been documented according to the different Malassezia species. ${ }^{22,33}$ The absence of rapid and simple identification methods may have serious implications in the administration of a prompt and appropriate therapy, especially when Malassezia yeasts are responsible for nosocomial bloodstream infections. ${ }^{6}$ Using the property of difference in fatty acid requirements of variants, some schemes have been devised to confirm the identity of the species by cultural methods. ${ }^{15,18}$ Nowadays, the Japanese system of identification has been proposed. ${ }^{25,26}$ It requires subculturing the isolated strain on several media as CHROMagar-Malassezia (CHROMM), Sabouraud Glucose Agar, Cremophor EL agar or Tween 60-Esculin agar. $^{2}$

The aim of this research was to evaluate the prevalence of Malassezia species in the superficial infection of the stratum corneum (pityriasis versicolor) in Rosario city, and to analyze their distribution according to patients' characteristics such as age, gender and site of lesions.

\section{Materials and methods}

Patients

A total of 264 patients ( 167 females and 97 male) with suspected PV diagnostic were evaluated. Their ages ranged from 5 to 60 years old. The study was conducted from April 2008 to December 2009 at the Mycology Reference Centre (CEREMIC), National University of Rosario, Santa Fe, Argentina. All patients were from Rosario city. Located in Argentina's central region, Rosario has temperate climate. A questionnaire was filled to get informative data about the family history, age, gender, location, clinical type and extent of disease in patients. The Human Ethics Committee rules were satisfied through informed consent.
Table 1

Reference strains.

\begin{tabular}{ll}
\hline Reference strains & Collection number \\
\hline M. slooffiae & JG 554= CBS 7956 \\
M. furfur & CBS 1878 \\
M. sympodialis & CBS 7222 \\
M. globosa & GM 7 and GM 35 = CBS 7966 \\
M. restricta & RA 42.2.C = CBS 7877 \\
M. pachydermatis & CBS 1337 \\
M. obtusa & I.N.E.I. 88 \\
\hline
\end{tabular}

CBS, Centraalbureau voor Schimmelcultures, Delft, The Netherlands; GM, Gillian Midgley, St Thomas' Hospital, London, UK; JG, Jacques Guillot, École Nationale Véterinaire College d'Alfort, Maisons-Alfort, France; RA, Ruth Ashbee, Department of Microbiology, University of Leeds, Leeds, UK; INEI, Instituto Dr. Carlos G. Malbrán, Buenos Aires, Argentina.

\section{Collection and culture of samples}

The samples from patients with suspected PV were obtained by scraping the patients' lesions with scalpel and adhesive tape. ${ }^{34}$

Specimens were examined by optic microscopy with Lactophenol Blue and by observation under fluorescence microscope with Calcofluor white. ${ }^{36}$

All samples collected were inoculated on modified Dixon's Agar (mDA) medium and Sabouraud Glucose Agar (SGA) with 2-3 drops of sterile olive oil, for 10 days at $32{ }^{\circ} \mathrm{C}$.

\section{Isolated yeasts}

When growth of Malassezia yeasts was detected on either mDA or SGA with 2-3 drops of sterile olive oil, they were selected and maintained by transfer on fresh medium (mDA) at biweekly intervals for their further identification.

Standard strains of the genus Malassezia were always used as control in the laboratory routine. They were M. pachydermatis, $M$. furfur, M. sympodialis, M. globosa, M. obtusa, M. restricta and M. slooffiae, which were provided by Dr Guillot (École Nationale Véterinaire College d'Alfort, Maisons-Alfort, France) and by the Dr Carlos Malbrán Institute (INEI-Micología, Buenos Aires, Argentina). Reference strains used are shown in Table 1.

\section{Phenotypic identification}

Malassezia species were identified in the first instance carrying out the scheme proposed by Guillot et al. ${ }^{18}$ at first moment. Moreover, the new scheme proposed by Kaneko et al. ${ }^{26}$ that requires modified CHROMagar-Malassezia medium, SGA, Tween 60-Esculin agar (EA), Cremophor El agar ( $\mathrm{CrEl}$ ) and catalase reaction, was proved. The latter scheme uses the following culture media:

Modified Dixon Agar (mDA): Strains of Malassezia were cultured and maintained on mDA composed by $6 \mathrm{~g}$ peptone (Oxoid), $36 \mathrm{~g}$ malt extract, $20 \mathrm{~g}$ ox bile (Oxoid), $2 \mathrm{ml}$ glycerol, $2 \mathrm{ml}$ oleic acid and $12 \mathrm{~g}$ agar per litre.

CHROMagar-Malassezia medium (CHROMM): Composed by 56.3 g CHROMagar-Malassezia basal medium (CHROMagar, Paris, France) and $10 \mathrm{ml}$ Tween 40 (per litre). ${ }^{25}$

Tween 60-Esculin Agar (EA): Composed by $10 \mathrm{~g}$ peptone, $10 \mathrm{~g}$ glucose, $2 \mathrm{~g}$ yeast extract, $0.5 \mathrm{~g}$ ferric ammonium citrate, $1 \mathrm{~g}$ esculin, $5 \mathrm{ml}$ of Tween 60 and $15 \mathrm{~g}$ agar (per litre). ${ }^{25}$

Utilization of Cremophor EL (CrEL): The capacity to grow on SGA supplemented with CrEL (partially-purified plant extract containing primarily, but not exclusively, ricinoleic acid) as unique lipid source.

Catalase reaction: The presence of catalase was determined by using a drop of hydrogen peroxide ( $30 \%$ solution).

The strains to be identified were placed on CHROMM, SGA and EA, incubating at $32^{\circ} \mathrm{C}$ for $4-7$ days. 


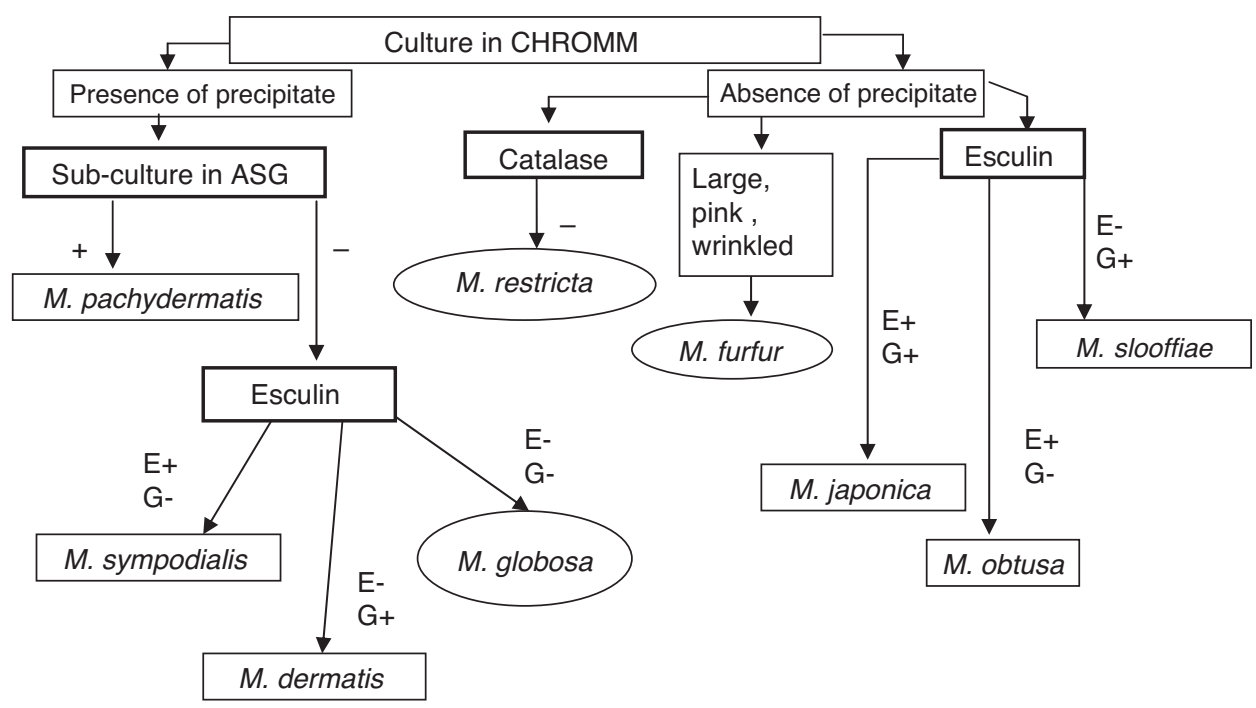

G: growth in EA

E: esculin hidrolysis

Fig. 1. Steps followed for the identification of Malassezia species.

The presence of precipitate and the morphology of the colony smooth or wrinkled - were checked in CHROMM. Subculture to SGA was used to determine the isolated lipid-dependence. EA evaluated the abilities of specimens to split the esculin showing $\beta$-glucosidase activity and the utilization or not of Tween 60 . Presence of catalase was evidenced by production of gas bubbles. The assimilation of $\mathrm{CrEl}$ was revealed by the production of growth area around this compound. The workflow used to identify species of Malassezia is shown in Fig. 1.

The specimens obtained and identified were conserved in $20 \%$ glycerol and $20 \%$ skim milk/20\% glycerol at $-70{ }^{\circ} \mathrm{C},{ }^{9}$ and in dried paper at room temperature. ${ }^{37}$

\section{Results}

The 264 patients were referred to the CEREMIC laboratory. The age of patients varied from 5 to 60 . Sixty three percent of the patients $(n=166)$ belonged to the range $25-45$ years of age.

The direct examination - with two different methods - gave positive samples in 219 cases (83\%). Forty five samples (17\%) were negative, and this latter group was not included in this study. Among the samples with direct examination showing a positive result, 107 (49\%) showed only filaments, and filaments and budding yeasts were observed in 112 samples (51\%).

Positive cultures were obtained in 200 samples (91\%) and negative in 19 samples ( $9 \%)$.

\section{Identification of clinical isolates}

Two hundred positive cultures were identified by phenotypic analysis. The remaining 19 samples did not yield any isolate in culture and the samples were not enough to repeat the study.

The scheme used for the identification of the isolates proposed by Kaneko et al., ${ }^{26}$ showed good results in our laboratory to identify species. All the clinical isolates showed positive catalase reaction.

Isolates that showed a precipitates in CHROMM (Fig. 2) and did not grow in SGA were lipid-dependent. In EA, 102 samples
(51\%) showed production of a black zone due to esculin hydrolysis products and ferrous iron. These tests positive results are compatible with M. sympodialis (Fig. 3). On the other hand, 80 samples (40\%) were negative to esculin hydrolisis and were identified as M. globosa.

Fourteen strains (7\%) out of $18(9 \%)$ that did not produce any precipitate in CHROMM (Fig. 2) were characteristically large, pale pink, wrinkled and compatible to M. furfur (Fig. 4). Two (1\%) were EA positive, and were identified as M. obtusa, whereas another 2 EA negative (1\%) were identified as $M$. slooffiae. The tests of growth with $\mathrm{CrEl}$ and splitting of esculin ( $\beta$-Glucosidase) were useful to confirm the identification of $M$. sympodialis, $M$. furfur and M. slooffiae. ${ }^{29}$

The reference strains followed the same scheme of identification and showed the expected results.

Among the 200 specimens, 59 were recovered from patients with two different body site lesions, and 2 from patients with three different body site lesions. Only one agent was recovered from these patients (Table 2).

The most frequently isolated species in PV lesions from all body sites analysed were $M$. sympodialis [102/200 (51\%)] and M. globosa [80/200 (40\%)], followed by M. furfur [14/200 (7\%)], M. obtusa $[2 / 200(1 \%)]$, and M. slooffiae [2/200 (1\%)]. From those 200 specimens, 192 (96\%) PV patients had a single Malassezia species in their lesions and $8(4 \%)$ had 2 species with a distribution as follows: $M$. sympodialis-M. globosa $(n=4) ;$ M. sympodialis-M. furfur $(n=2)$ and $M$. furfur-M. globosa $(n=2)$. M. obtusa and $M$. slooffiae, known to be relatively uncommon species in general, were obtained from single PV lesion.

\section{Discussion}

Similar to other researches, 8,38,21 the highest prevalence of PV in this study was observed in the 25- to 45-year-old group, suggesting that the peak of the infection coincides with ages when the sebum production is in its highest level.

The role of sex in propensity to develop of PV is still unclear. Some studies found that PV is more common in men than in 


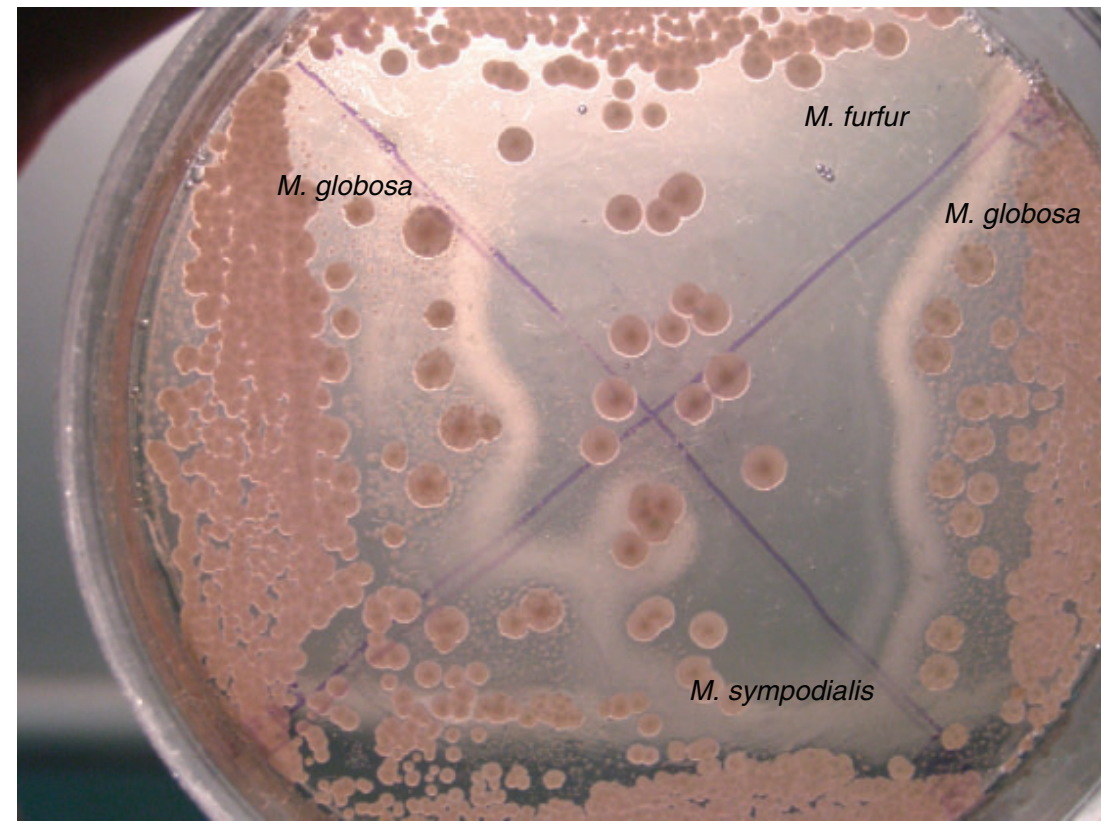

Fig. 2. Precipitate production on modified CHROMagar-Malassezia medium. Malassezia species were incubated for 4 days at $32{ }^{\circ} \mathrm{C}$ on $\mathrm{CHROMM}$.

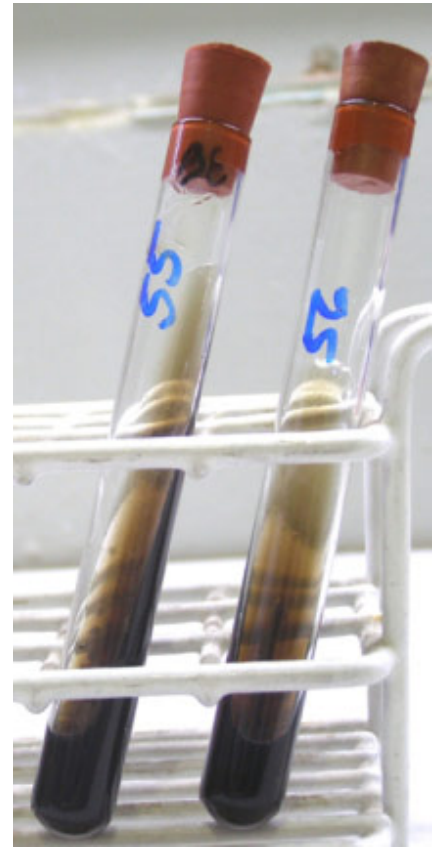

Fig. 3. Production of black zone in Esculin agar by M. sympodialis. women, ${ }^{7,10}$ while others indicated that the incidence of these infections is higher in women, ${ }^{20}$ which may be due to extra attention of women to beauty and the more frequent visits to their dermatologist in comparison to men. However, like many reports, ${ }^{11,19}$ this study has found no differences in the development of PV between both sexes. (The $P$-values $<0.05$ were required to consider statistically significant difference.)

In the present study, the most affected areas of the body were trunk and face, in concordance with the majority of studies worldwide. 1,31,40 The back and the arms were the second most commonly affected sites, followed by the neck. Similar to other studies, ${ }^{40}$ we found no statistical difference in the distribution of Malassezia species on various body sites $(P>0.01)$. This might be related to the frequent presence of patients with extensive PV lesions. ${ }^{13}$

When possible, the direct examination with Calcofluor white is recommended. This compound has high affinity for the chitin present in the fungal cell wall and in the budding zone. Hence, extra information, such as budding pattern, may be obtained. ${ }^{36}$

Culture is necessary to distinguish between the Malassezia species by morphological and physiological methods because the detection of a mixed infection would be important when the species have different responses to antifungal agents. ${ }^{13}$

In our study, the recovery rate of Malassezia species was $91 \%$ (200 samples), which showed good concordance with a recent study carried out by Nakabashi et al., ${ }^{32}$ and higher than some previous studies. ${ }^{19,40}$ The difference may be due to the fact that the

Table 2

Distribution of Malassezia species isolated from specimens studied.

\begin{tabular}{|c|c|c|c|c|c|c|}
\hline Body sites & $n$ & M. sympodialis & M. globosa & M. furfur & M. obtusa & M. slooffiae \\
\hline Arms & 15 & 8 & 5 & 1 & 1 & \\
\hline Back & 24 & 10 & 9 & 4 & 1 & \\
\hline Face & 35 & 17 & 14 & 3 & & 1 \\
\hline Face-arms & 28 & 17 & 9 & 2 & & \\
\hline Trunk & 66 & 41 & 24 & & & 1 \\
\hline Trunk-face & 15 & 7 & 6 & 2 & & \\
\hline Trunk-arms & 15 & 2 & 11 & 2 & & \\
\hline Trunk-arms-face & 2 & & 2 & & & \\
\hline Total & 200 & 102 & 80 & 14 & 2 & 2 \\
\hline
\end{tabular}



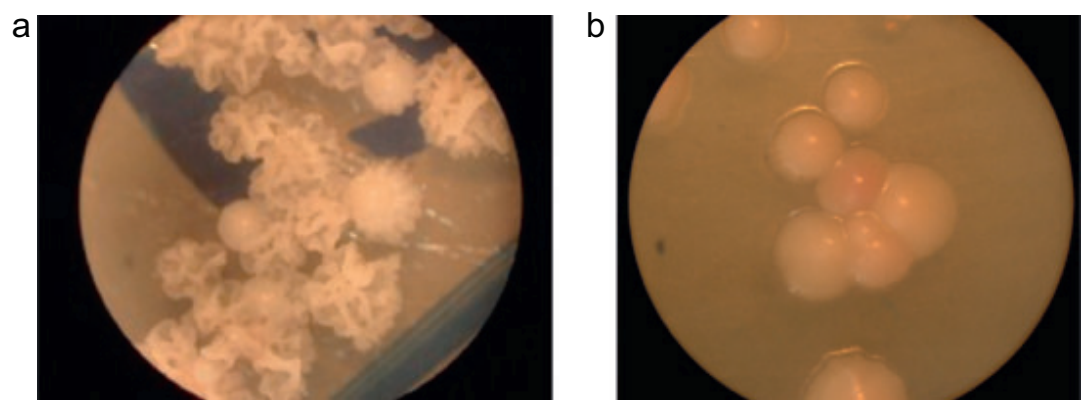

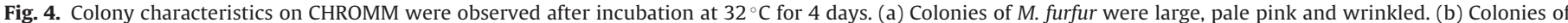
M. sympodialis were large, pale pink and smooth.

centre of the PV lesions yields more viable material for culture $8,9,11$ and avoid the isolation of surrounding commensal species. ${ }^{38,44}$

In the patients studied, the most frequently isolated species in PV lesions were $M$. sympodialis (51\%) and M. globosa (40\%), followed by M. furfur (7\%), M. obtusa (1\%), and M. slooffiae (1\%). These results are comparable with those founded by Canteros et al. ${ }^{5}$ in Buenos Aires city (central region of Argentina) and Giusiano et al. $^{13}$ in Chaco city (Argentine northeast). Gupta et al. ${ }^{19,20}$ in Ontario, Canada, found M. sympodialis as the main agent of PV in temperate climate regions and $M$. globosa as the predominant agent in tropical regions. However, Rasi et al. ${ }^{38}$ found $M$. globosa as the main agent of PV lesions in temperate region of Iran. In contrast, other studies, mainly carried out in areas with tropical or subtropical climates, showed a predominance of $M$. furfur in PV lesions. ${ }^{2}$ Makimura et al. ${ }^{27}$ in Japan, by molecular identification of the species, observed $M$. furfur and $M$. sympodialis as the predominant agents of PV, but not M. globosa. Species different from M. globosa, which is mainly observed in Northern countries, might predominate in PV in other climates. Hence, more studies are necessary to either confirm or reject this hypothesis. ${ }^{2}$ Further, the differences among these studies may be explained by different sampling techniques (scraping/contact plaques), the use of culture and non-culture methods and different culture media (modified Dixon agar/Leeming-Notman agar). There are probably geographical variations, that might influence the species recovered. ${ }^{31}$

Culture is not necessary for routine diagnosis, but is indispensable to recognize the species involved in the disease. ${ }^{2}$ The usefulness of the study of morphological characteristics for the differentiation of Malassezia species is rather subjective since it depends, to a large extent, on the observer and the conditions of the test, which can be subject to variation according to the culture medium employed and the temperature at which it is performed. Besides, identification of these species based on a microscopic observation is not able to provide unequivocal results. Thus, a simple, reliable and cost-effective identification method is required in most clinical laboratories. ${ }^{26}$ Physiological tests, namely culture in CHROMM, catalase test, lipidic dependence and esculin test are useful to achieve a correct identification of clinically important Malassezia species in our region. The employed methodology ${ }^{26}$ is suitable for the identification of dermatologic significant $M$. furfur, $M$. globosa and $M$. restricta species with a specificity of $100 \%$ and $M$. sympodialis with a specificity of $97.7 \%$. Furthermore, using CHROMM as primary culture allows the detection of mixture of species directly from specimens due to the different characteristic that Malassezia species present in this differential culture medium.

At present, an increase in the isolation of M. globosa is being observed in patients with PV diagnosis (unpublished data) in our city. This is probably due to the climate changes our region is suffering (temperate climate originally) and how these variations modify the ecology of Malassezia genus. Isolation and identification of the different species is necessary to deepen the knowledge of regional epidemiology and ecology of the strains of Malassezia and their relationship with dermatologic disorders. Hence, systematically sampling and recording epidemiological data from hosts residing in various geographical locations and correlating with pathophysiological and environmental information could improve management of Malassezia associated infections and provide biological insights.

\section{Conflict of interest}

The authors have no conflict of interest to declare.

\section{Acknowledgments}

Reference strains used in this work were kindly provided by Dr J. Guillot (École Nationale Véterinaire College d'Alfort, Maisons-Alfort, France) and by the Dr. Carlos Malbrán Institute (INEI-Micología, Buenos Aires, Argentina).

\section{References}

1. Belec L, Testa J, Bouree P. Pityriasis versicolor in the Central African Republic: a randomized study of 144 cases. J Med Vet Mycol. 1991;29:323-9.

2. Boekhout T, Guého-Kellerman E, Mayser P, Velegraki A, editors. Malassezia and the skin science and clinical practice. Heidelberg/Dordrecht/London/New York: Springer; 2010.

3. Cabañes FJ, Theelen B, Castellá G, Boekhout $T$. Two new lipid-dependent Malassezia species from domestic animals. FEMS Yeast Res. 2007;6:1064-76.

4. Cabañes FJ, Vega S, Castellá C. Malassezia cuniculi sp. nov., a novel yeast species isolated from rabbit skin. Med Mycol. 2011;49:40-8.

5. Canteros CE, Soria M, Rivas C, Lee W, López Joffre MC, Rodero L, et al. Especies de Malassezzia aisladas de patologías de piel en un centro asistencial de la ciudad de Buenos Aires, Argentina. Rev Argent Microbiol. 2003;35:156-61.

6. Chang HJ, Miller HL, Watkins NW. An epidemic of Malassezia pachydermatis in an intensive care unit nursery associated with colonization of health care workers pet dogs. N Engl J Med. 1998;338:706-11.

7. Crespo Erchiga V, Ojeda Martos A, Vera Casaño A, Crespo Erchiga A, Sánchez Fajardo F. Aislamiento e identificación de Malassezia spp. en pitiriasis versicolor, dermatitis seborreica y piel sana. Rev Iberoam Micol. 1999;16:16-21.

8. Crespo Erchiga V, Ojeda Martos A, Vera Casaño A, Crespo Erchiga A Sánchez Fajardo F, Guého E. Mycology of pityriasis versicolor. J Mycol Med. 1999;9:143-8.

9. Crespo MJ, Abarca ML, Cabañes FJ. Evaluation of different preservation and storage method for Malassezia spp. J Clin Microbiol. 2000;38:3872-5.

10. Crespo Erchiga V, Delgado FV. Malassezia species in skin diseases. Curr Opin Infect Dis. 2002;15:133-42.

11. Dutta S, Bajaj AK, Basu S, Dikshit A. Pityriasis versicolor: socioeconomic and clinico-mycologic study in India. Int J Dermatol. 2002;41:823-4.

12. Fitzpatrick TB, Johnson RA, Wolff K, Suurmond D. Color atlas \& synopsis of clinical dermatology. 4th ed. New York: Mc Graw Hill; 2001.

13. Giusiano G, Sosa MA, Rojas F, Vanacore ST, Mangiaterra M. Prevalence of Malassezia species in pityriasis versicolor lesions in northeast Argentina. Rev Iberoam Micol. 2010;27:71-4.

14. Guého E, Meyer SA. A reevaluation of the genus Malassezia by means of genoma comparison. Antonie van Leeuwenhoek. 1989;55:245-51.

15. Guého E, Midgley G, Guillot J. The genus Malassezia with description of four new species. Antonie van Leeuwenhoek. 1996;69:337-55. 
16. Guého E, Boekhout T, Ashbe HR, Guillot J, van Belkum A, Faergemann J. The role of Malassezia species in the ecology of human skin and as pathogens. Med Mycol. 1998;36:220-9.

17. Guillot J, Guého E, Prévost MC. Ultraestructural features of the dimorphic yeast species Malassezia furfur. J Mycol Med. 1995;5:86.

18. Guillot J, Guého E, Lesourd M, Midgley G, Chévrier G, Dupont B. Identification of Malassezia species: a practical approach. J Mycol Med. 1996;6:103-10.

19. Gupta AK, Kohli Y, Faergemann J, Summerbell RC. Epidemiology of Malasezia yeasts associated with pityriasis versicolor in Ontario, Canada. Med Mycol. 2001;39:199-206.

20. Gupta AK, Kohli Y, Summerbell RC, Faergemann J. Quantitive culture of Malassezia species from different body sites of individuals with or without dermatoses. Med Mycol. 2001;39:243-51.

21. Gupta AK, Bluhm R, Summerbell R. Pityriasis versicolor. J Eur Acad Dermatol Venereol. 2002;16:19-33.

22. Hammer KA, Carson CF, Riley TV. In vitro activities of ketoconazole, econazole, miconazole and Maleleuca alternifolia (tea tree) oil against Malassezia species. Antimicrob Agents Chemother. 2000;44:467-9.

23. Hazen KC. New and emerging yeast pathogens. Clin Microbiol Rev. 1995;8: 462-78.

24. Hirai A, Kano R, Makimura K, Duarte E, Hamdan J, Lachance M, et al. Malassezia nana sp. nov., a novel lipid-dependent yeast species isolated from animals. Int J Evol Microbiol. 2004;54:623-7.

25. Kaneko T, Makimura K, Sugita T, Yamaguchi H. Tween 40-based precipitate production observed on modified chromogenic agar and development of biological identification kit for Malassezia species. Med Mycol. 2006;44:227-31.

26. Kaneko T, Makimura K, Abe M, Shiota R, Nakamura Y, Kano R, et al. Revised culture-based system for identification of Malassezia species. J Clin Microbiol. 2007; 45:3737-42.

27. Makimura K, Tamura Y, Kudo M, Uchida K, Saito H, Yamaguchi H. Species identification and strain typing of Malassezia species stock strains and clinical isolates based on the DNA sequences of nuclear ribosomal internal transcribed spacer I regions. J Med Microbiol. 2000;49:29-35.

28. Marcon MS, Powell DA. Human infections due to Malassezia spp. Clin Microbiol Rev. 1992:5:101-19.

29. Mayser P, Haze P, Papavassilis C, Pickel M, Gründer K, Guého E. Differentation of Malassezia species: selectivity of Cremophor EL, castor oil and ricinoleic acid for M. furfur. Br J Dermatol. 1997;137:208-13.

30. Midgley G, Guého E, Guillot J. Disease caused by Malassezia species. In: Ajello L Hay RJ, editors. Topley and Wilson's microbiology and microbial infections, vol. 4, 9th ed. London: Arnold; 1998. p. 201-11.
31. Midgley G. The lipophilic yeasts: state of the art and prospects. Med Mycol. 2000;38:9-16

32. Nakabayashi A, Sei Y, Guillot J. Identification of Malassezia species isolated from patients with seborrhoeic dermatitis, atopic dermatitis, pityriasis versicolor and normal subjects. Med Mycol. 2000;38:337-41.

33. Nakamura Y, Kano R, Murai T, Watanabe S, Hasegawa A. Susceptibility testing of Malassezia species using the urea broth microdilution method. Antimicrob Agents Chemother. 2000;44:2185-6.

34. Padhila-Goncalves A. A single method to strain Malassezia furfur and Corynebacterium minutissimum in scales. Rev Inst Med Trop Sao Paulo. 1996;38. 299-302.

35. Perfect JR, Schell WA. The new fungal opportunists are coming. Clin Infect Dis. $1996 ; 22: 5112-8$

36. Ramos L, Mellado S, Ramadán S, Bulacio L, López C. The use of calcofluo white for identification of Malassezia species. Rev Argent Microbiol. 2006;38: 4-8.

37. Ramos L, Ramadán S, López C, Bulacio L, Mellado S. Empleo de discos de pape secante para la conservación de cepas de Malassezia spp. Rev Iberoam Micol 2006;23:110-2.

38. Rasi A, Naderi R, Behzadi AH, Falahati M, Farehyar S, Honarbakhsh Y, et al Malassezia yeast species isolated from Iranian patients with pityriasis versicolor in a prospective study. Mycoses. 2010;53:350-5.

39. Simons RB, Guého E. A new species of Malassezia. Mycol Res. 1990;94:146-9.

40. Sugita T, Uto H, Unno T, Tsuboi R, Ogawa H, Shinoda T, et al. Molecular analysis of Malassezia microflora on the skin of atopic dermatitis patients and healthy subjects. J Clin Microbiol. 2001;39:3486-90.

41. Sugita T, Takashima M, Shinoda T, Suto H, Unno T, Tsuboi R, et al. New yeast species, Malassezia dermatis, isolated from patients with atopic dermatitis. Clin Microbiol. 2002;40:1363-7.

42. Sugita T, Takashima M, Kodama M, Tsuboi R, Nishikawa A. Description of the new yeast species, Malassezia japonica, and its detection in patients with atopic dermatitis and healthy subjects. J Clin Microbiol. 2003;41: 4695-9.

43. Sugita T, Tajima M, Takashima M, Amaya M, Saito M, Tsuboi R, et al. A new yeast, Malassezia yamatoensis, isolated from a patient with seborrheic dermatitis, and its distribution in patients and healthy subjects. Microbiol Immunol 2004;48:579-83.

44. Tarazooie B, Kordbacheh P, Zaini F, Zomorodian K, Saadat F, Zeraati H, et al Study of the distribution of Malassezia species in patients with pityriasis versicolor and haelthy individuals in Teheran, Iran. BMC Dermatol. 2004;4 $1-6$ 